\title{
Unseasonal development of post-sunset F- region irregularities over Southeast Asia on 28 July 2014: 2. Forcing from below?
}

\author{
K. K. Ajith', S. Tulasi Ram ${ }^{1 *}$ (D, B. A. Carter ${ }^{2}$, S. Sathish Kumar ${ }^{3}$, M. Yamamoto ${ }^{4}$, T. Yokoyama ${ }^{5}$, S. Gurubaran? \\ S. Sripathi ${ }^{1}$, K. Hozumi ${ }^{5}$, K. Groves ${ }^{6}$ and R. G. Caton ${ }^{7}$
}

\begin{abstract}
An unseasonal development of Equatorial Plasma Bubble (EPB)/Equatorial Spread-F (ESF) activity in a wide longitudinal sector over India and Southeast Asia during the post-sunset hours of 28 July 2014 has been investigated in detail using the multiple independent observations in this paper and a companion paper by (Prog Earth Planet Sci 5:10, 2018). This post-sunset ESF/EPB event was preceded by a substantial elevation of the equatorial F-layer due to strong pre-reversal enhancement (PRE) during the season which is climatologically unfavorable for strong PRE and post-sunset EPBs. In this paper, it is found that a strong equatorward meridional neutral wind at off-equatorial E-region and enhanced longitudinal gradient of equatorial electrojet appear to be the responsible candidates for the enhanced PRE and EPB development on 28 July 2014. These changes in the local wind system and PRE are found to have an apparent connection with the planetary wave forces of lower atmospheric origin. Both the post-sunset height rise (PSSR) and lower thermospheric meridional neutral wind consistently exhibit quasi-2-day planetary wave-like oscillations during 20-31 July 2014 with maximum amplitudes on 28 July 2014. This study emphasizes the role of planetary wave forces from the lower atmosphere that can alter the local neutral wind system and E-region conductivities that may lead to the development of strong PRE and EPB activity which were otherwise climatologically unfavorable for post-sunset EPB/ESF development.
\end{abstract}

Keywords: Equatorial plasma bubbles, Pre-reversal enhancement, Neutral winds

\section{Introduction}

The development of Equatorial Spread-F (ESF)/Equatorial Plasma Bubble (EPB) irregularities in the nighttime equatorial ionosphere has been studied for several decades since it was first reported by Booker and Wells (1938). From the detailed studies by several researchers, the general morphological features of EPBs such as the occurrence variability with local time, season, latitude, longitude, solar cycle, and geomagnetic activity were more or less thoroughly understood (Abdu et al. 1981; Kelley and McClure 1981; Tsunoda 1985; Rama Rao et al. 2005; Tulasi Ram et al. 2008; Kumar et al. 2016). However, the anomalous day-to-day variability in the occurrence of EPBs still remains to puzzle the researchers over the years.

\footnotetext{
* Correspondence: s.tulasiram@gmail.com

${ }^{1}$ Indian Institute of Geomagnetism, Navi Mumbai, India

Full list of author information is available at the end of the article
}

Because of their potential impact on trans-ionospheric radio communications and satellite-based navigation systems, EPBs have drawn wide attention and become one of the important topics of space weather interest today (Kelley et al. 2011; Woodman 2009).

The ESF/EPB irregularities generally initiate at the bottom side F-layer through the Rayleigh-Taylor (RT) instability (Haerendel 1973) and grow nonlinearly to the topside ionosphere via polarization electric fields within them. The pre-reversal enhancement (PRE) of the equatorial zonal electric field and steep vertical density gradient due to bottom side recombination sets the conditions most favorable for the development of EPBs during the post-sunset hours (Farley et al. 1986; Tulasi Ram et al. 2006). Further, the spatial large-scale wave structure (LSWS) at the base of F-layer is believed to be the potential seed for the development of EPBs and 
determines the location of bubble onset (Tsunoda and White 1981; Tsunoda 2005; Tsunoda et al. 2011; Tulasi Ram et al. 2012, 2014). Besides the PRE and initial seeding by LSWS, the symmetrical plasma distribution in the conjugate hemispheres and meridional neutral winds also play significant roles for determining the onset of EPBs (Maruyama and Matuura 1984; Maruyama 1988).

Among the above necessary favorable conditions, the post-sunset height rise (PSSR) of equatorial F-layer via the PRE is known to be the most important factor. It is also often shown that the EPBs would always develop when the equatorial F-layer is elevated to sufficiently higher altitudes (Farley et al. 1970; Rastogi 1980; Kelley and Maruyama 1992; Fejer et al. 1999; Anderson et al. 2004; Tulasi Ram et al. 2006, 2007; Li et al. 2007; Huang and Hairston 2015). However, the strength of the PRE (and PSSR) itself exhibits significant day-to-day variability (Scherliess and Fejer 1999), thereby leaving the early prediction of EPBs far from the reality. The PRE is generally large during the seasons when the sunset terminator is closely aligned with the local magnetic meridian (Abdu et al. 1981; Tsunoda 1985). The close alignment of the sunset terminator with the magnetic meridian causes simultaneous decay of E-region conductivity at both ends of the field line and maximizes the strength of the PRE. Therefore, over Indian and Southeast Asian longitudes where the magnetic declination is close to zero, the PRE strength maximizes during equinoxes and becomes weaker during solstices (e.g., Tulasi Ram et al. 2006). As a result, the occurrence of post-sunset EPBs maximizes during the equinoxes and becomes lowest during the solstices, particularly during the June solstices over Indian and Southeast Asian sector (e.g., Retterer and Gentile 2009; Otsuka et al. 2009; Ajith et al. 2015). There can be another class of EPBs that develop around post-midnight hours of June solstices over Indian and Southeast Asian sector which have different characteristics compared to post-sunset EPBs (Otsuka and Ogawa 2009; Dao et al. 2016; Ajith et al. 2016). However, the present investigation is focused only on the post-sunset EPBs that are associated with PRE and PSSR.

In contrast to the generally known morphology, the PRE may be occasionally suppressed during equinoxes and, conversely, can be enhanced during solstices, thereby instituting enigmatic day-to-day variability even under quiet geomagnetic conditions. Such unseasonal cases of PRE suppression during equinoxes and enhancement during solstices are difficult to predict. Despite some recent success in using coupled thermosphere-ionosphere modeling to describe day-to-day EPB variability during equinox periods (e.g., Carter et al. 2014a, 2014b, 2014c), EPB occurrence during solstices is not well predicted by either theoretical or climatological models, and even by the more sophisticated self-consistent Thermosphere-Ionosphere Electrodynamics General Circulation Model (TIEGCM) (e.g. Carter et al. 2014c). Investigating such unseasonal cases in greater detail can advance our understanding on the possible factors responsible for the day-to-day variability in the PRE and EPB occurrence. In the present paper (and in a companion paper by Carter et al. 2018), we report and investigate an interesting case of unseasonal enhancement of PRE and development of EPBs during the post-sunset hours on July 28, 2014, over a wide sector of Indian and Southeast Asian longitudes.

\section{Methods/Experimental}

An interesting unseasonal EPB event on July 28, 2014, and the responsible factors have been investigated using a suite of ground-based observations, such as Equatorial Atmosphere Radar (EAR), magnetometers, ionosondes, MF radar, and VHF scintillation observations spanning over Indian and Southeast Asian longitudes. Figure 1 shows the locations of various observatories considered in the present study. The $47-\mathrm{MHz}$ Equatorial Atmosphere Radar (EAR) in Kototabang, Indonesia $\left(0.20^{\circ} \mathrm{S}\right.$, $100.32^{\circ} \mathrm{E}, 10.36^{\circ} \mathrm{S}$ dip latitude) is routinely operated with a peak and average powers of $100 \mathrm{~kW}$ and $5 \mathrm{~kW}$, respectively, to study the F-region field-aligned irregularities (FAIs) at $\sim 3 \mathrm{~m}$ scale size during night times (1800$0600 \mathrm{LT})$. The EAR is regularly operated with two sets of 8 beams (total 16 beams) in F-region mode that sequentially scans the beam directions on a pulse-to-pulse basis (Fukao et al. 2003). In the present study, the backscatter echoes and radial Doppler velocities obtained mainly from the central (azimuth $=180^{\circ}$ ) beam of the EAR were considered. The background ionospheric conditions such as post-sunset height rise (PSSR) and the occurrence of ESF over Indian and Southeast Asian longitudes were examined by three ground-based ionosondes at Tirunelveli, India $\left(8.7^{\circ} \mathrm{N}, 77.7^{\circ} \mathrm{E}, 1.67^{\circ} \mathrm{N}\right.$ dip$)$; Bac Lieu, Vietnam $\left(9.29^{\circ} \mathrm{N}, 105.71^{\circ} \mathrm{E}, 1.5^{\circ} \mathrm{N}\right.$ dip latitude); and Sanya, China $\left(18.4^{\circ} \mathrm{N}, 109.6^{\circ} \mathrm{E}, 12.8^{\circ} \mathrm{N}\right.$ dip latitude). Further, the VHF scintillation observations from low-latitude stations Kolkata (previously known as Calcutta), India $\left(22.58^{\circ} \mathrm{N}, 88.38^{\circ} \mathrm{E}, 13.19^{\circ} \mathrm{N}\right.$ dip latitude) and Chung-Li, Taiwan $\left(22.5^{\circ} \mathrm{N}, 121.4^{\circ} \mathrm{E}, 12.8^{\circ} \mathrm{N}\right.$ dip latitude) were considered to examine the VHF scintillation activity on 28 July 2014 . The role of the equatorial electrojet (EEJ) current on the PRE is examined using the three magnetometers located at equatorial stations, Addis Ababa $\left(8.98^{\circ} \mathrm{N}, 38.76^{\circ} \mathrm{E}, 0.5^{\circ} \mathrm{S}\right.$ dip latitude), Tirunelveli $\left(8.7^{\circ} \mathrm{N}, 77.7^{\circ} \mathrm{E}, 0.9^{\circ} \mathrm{N}\right.$ dip latitude), and Phuket $\left(7.89^{\circ} \mathrm{N}, 98.39^{\circ} \mathrm{E}, 0.15^{\circ} \mathrm{S}\right.$ dip latitude). Also, the possible role of the equatorward meridional wind on the PRE on July 28,2014 , is examined using hourly neutral wind data obtained the medium frequency $(2 \mathrm{MHz})$ partial reflection (PR) radar at Kolhapur $\left(16.7^{\circ} \mathrm{N}, 74.3^{\circ}\right.$ 


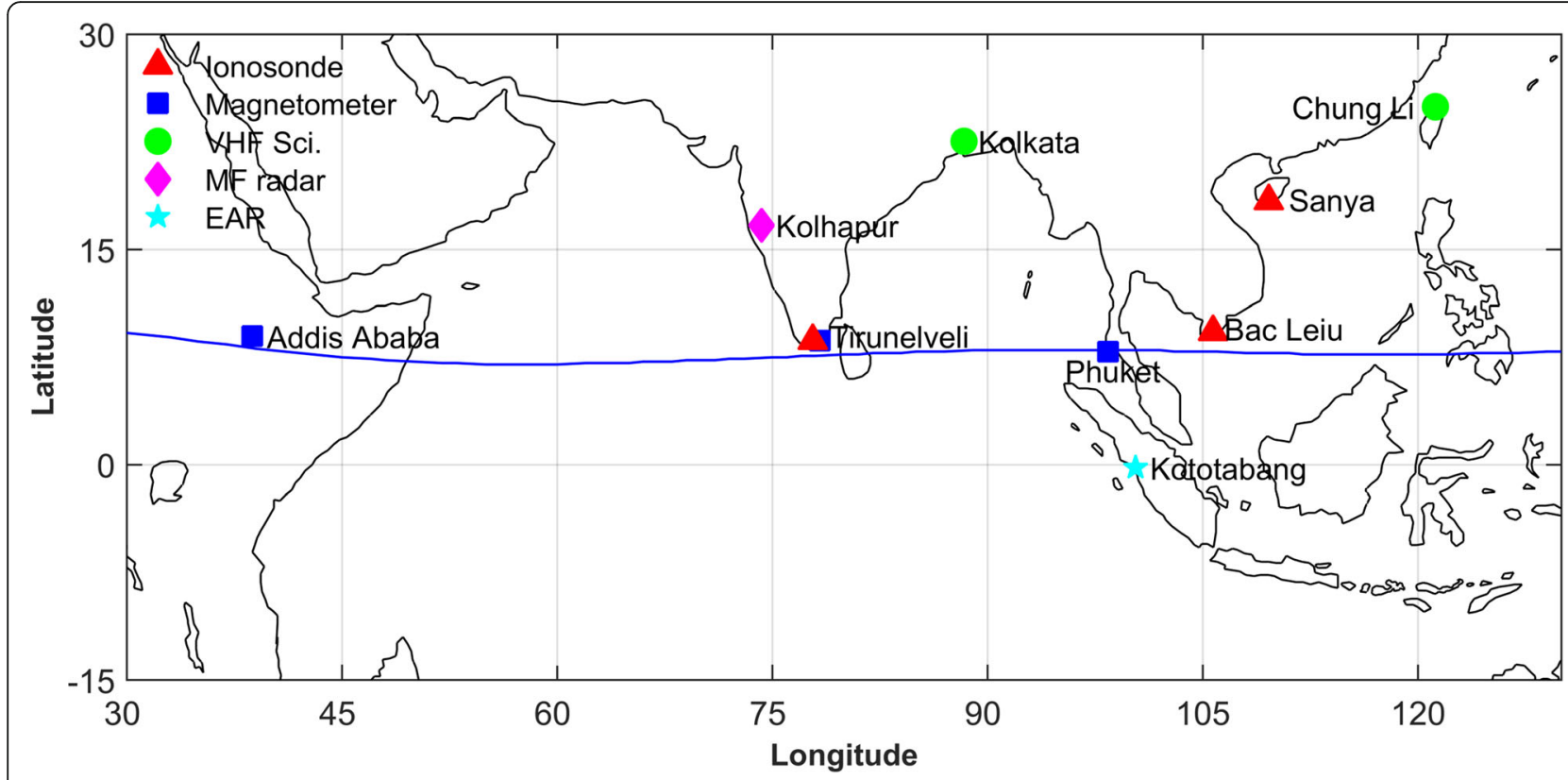

Fig. 1 The geographic locations of different instruments used in the present study. The blue line indicates the geomagnetic equator

E, $11.5^{\circ} \mathrm{N}$ dip latitude). This radar operates in a spaced antenna mode and determines the wind field by a full correlation analysis (Gurubaran and Rajaram 1999).

\section{Results}

Figure 2a shows the altitude-time-intensity (ATI) map of backscatter echoes from the field-aligned irregularities (FAIs) at $\sim 3 \mathrm{~m}$ scale size observed from the central beam (azimuth $=180^{\circ}$ ) of the EAR on 28 July 2014 over Kototabang, Indonesia. The corresponding Doppler velocity obtained from single-beam F-region Doppler mode observations from the central beam of the EAR is shown in Fig. 2b. From Fig. 2a, b, one can observe the strong plume-like structures between $\sim 1245$ and 1645 UT ( 1945 to 2345 LT) on 28 July 2014. These FAI echoes are very intense $(>30 \mathrm{~dB})$ and have risen beyond the maximum range of EAR $(\sim 510 \mathrm{~km})$ in this measurement mode. Further, these FAI echoes exhibit strong upward drift (negative Doppler velocity) with velocities greater than $100 \mathrm{~m} / \mathrm{s}$ (Fig. 2b) during $\sim 1245$ to 1430 UT. Hence, the results from Fig. $2 \mathrm{a}, \mathrm{b}$ indicate that these FAI echoes are from active and upwelling plume-like EPBs developed over EAR longitudes. Later around 1830 UT (0130 LT), another small EPB echo is observed during the post-midnight hours. From the fan sector backscatter maps (not shown in the figure) constructed from the 16 beam observations of EAR (Ajith et al. 2015), it is further confirmed that the observed post-sunset EPBs on 28 July 2014 are freshly developed over EAR longitudes, and the small post-midnight EPB around $1830 \mathrm{UT}$ is drifting into the field of view (FoV) of EAR from the western longitudes.

The ESF/EPB activity on this day (28 July 2014) has also been observed as range Spread-F echoes from ionosondes at Tirunelveli, Bac Lieu, and Sanya which are spread over Indian and Southeast Asian longitudes. Carter et al. (2018), in the companion paper, have also shown that the scintillation activity at the GPS-L1 frequency is widespread over Indian and Southeast Asian longitudes on 28 July 2014 using ground-based GPS and COSMIC/Formosat-3 Radio Occultation observations. In this study, we further examined the VHF scintillation $(\sim 250 \mathrm{MHz})$ observations from the Scintillation Network Decision Aid (SCINDA) network (Groves et al. 1997). For example, Fig. 3a, b shows the S4-index as a function of universal time on the night of 28 July 2014 from Kolkata, India $\left(22.58^{\circ} \mathrm{N}, 88.38^{\circ} \mathrm{E}, 13.19^{\circ} \mathrm{N}\right.$ dip latitude) and Chung-Li, Taiwan $\left(22.5^{\circ} \mathrm{N}, 121.4^{\circ} \mathrm{E}\right.$, $12.8^{\circ} \mathrm{N}$ dip latitude), respectively. The geographic locations of these stations can be observed in Fig. 1. It can be observed in Fig. 3a, b that the strong VHF scintillation occurred at both Kolkata and Chung-Li indicating that the EPBs were developed over a wide sector over Indian and Southeast Asian longitudes $\left(77^{\circ} \mathrm{E}\right.$ to $\left.121^{\circ} \mathrm{E}\right)$ on that night.

Figure 4 shows the stacked ATI plots of backscatter FAI echoes observed from the EAR for all days in the month of July 2014. The white portions in Fig. 4 indicate lack of data (no observation). It can be seen from this figure that the EPB activity over EAR location is completely absent in the month of July, except on 28 July. 


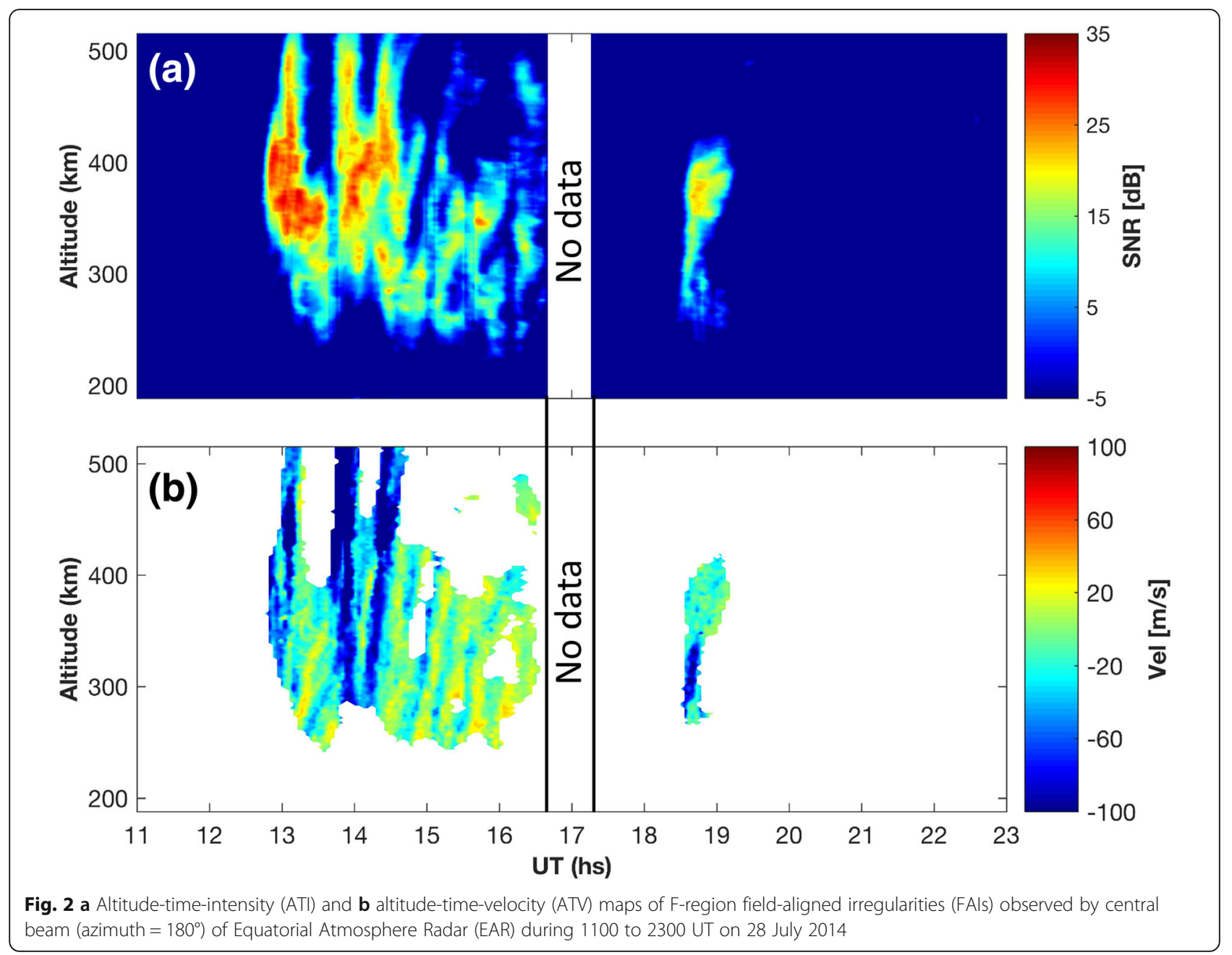

Also, no significant VHF scintillations at Kolkata and Chung-Li were observed during the post-sunset hours of this month, except on this event day (not shown in the figure). Therefore, this is a unique case of enhanced EPB activity on 28 July 2014 over Indian and Southeast Asian longitudes, where the PRE is generally weak/absent during July and not favorable for the development of post-sunset EPBs.

Now, in effort to examine the background PRE conditions on this day, we analyzed the F-layer base height ( $h$ ' F) observed from two equatorial ionosondes at Bac Lieu, Vietnam, and Tirunelveli, India. Figure $5 \mathrm{a}, \mathrm{b}$ shows the nighttime h'F variations from the ionosondes at two equatorial stations, Bac Lieu and Tirunelveli, respectively. In Fig. 1, it is clear that both stations are located close to the magnetic equator and separated by $\sim 28^{\circ}$ in longitude. The red curves in Fig. 5 show the h'F variations on 28 July 2014, and the blue curves with error bars represent the monthly mean h'F variations of July 2014 excluding 28 July. The gray dots indicate the variation of h'F values on individual days during July 2014 at $10 \mathrm{~min}$ interval. The horizontal line in light blue color in Fig. $5 \mathrm{a}, \mathrm{b}$ indicates the occurrences and the durations of Spread-F observed at the respective stations on 28 July. Note that the scaling of h'F from ionosondes under intense Spread-F conditions can be ambiguous, so the $h^{\prime}$ F variations on 28 July (red curves) were not shown after the onset of Spread-F. It can be seen in Fig. 5a that the equatorial F-layer on 28 July exhibits a significant post-sunset height rise (PSSR) over Bac Lieu and reaches to a maximum altitude of $\sim 380 \mathrm{~km}$ at 1200 UT ( 1900 LT). Similarly, h'F over Tirunelveli also rose to an altitude of $\sim 440 \mathrm{~km}$ at $1450 \mathrm{UT}(\sim 1950$ LT) during the post-sunset hours (Fig. 5b). The large PSSR at both Bac Lieu and Tirunelveli on 28 July (red curves) compared to their monthly mean values (blue curves with error bars) indicate that the PRE is significantly enhanced over Indian and Southeast Asian longitudes on this day. Further, the Spread-F started to occur just after the peak PSSR and lasted for several hours as shown by the horizontal lines in light blue color at both stations. 


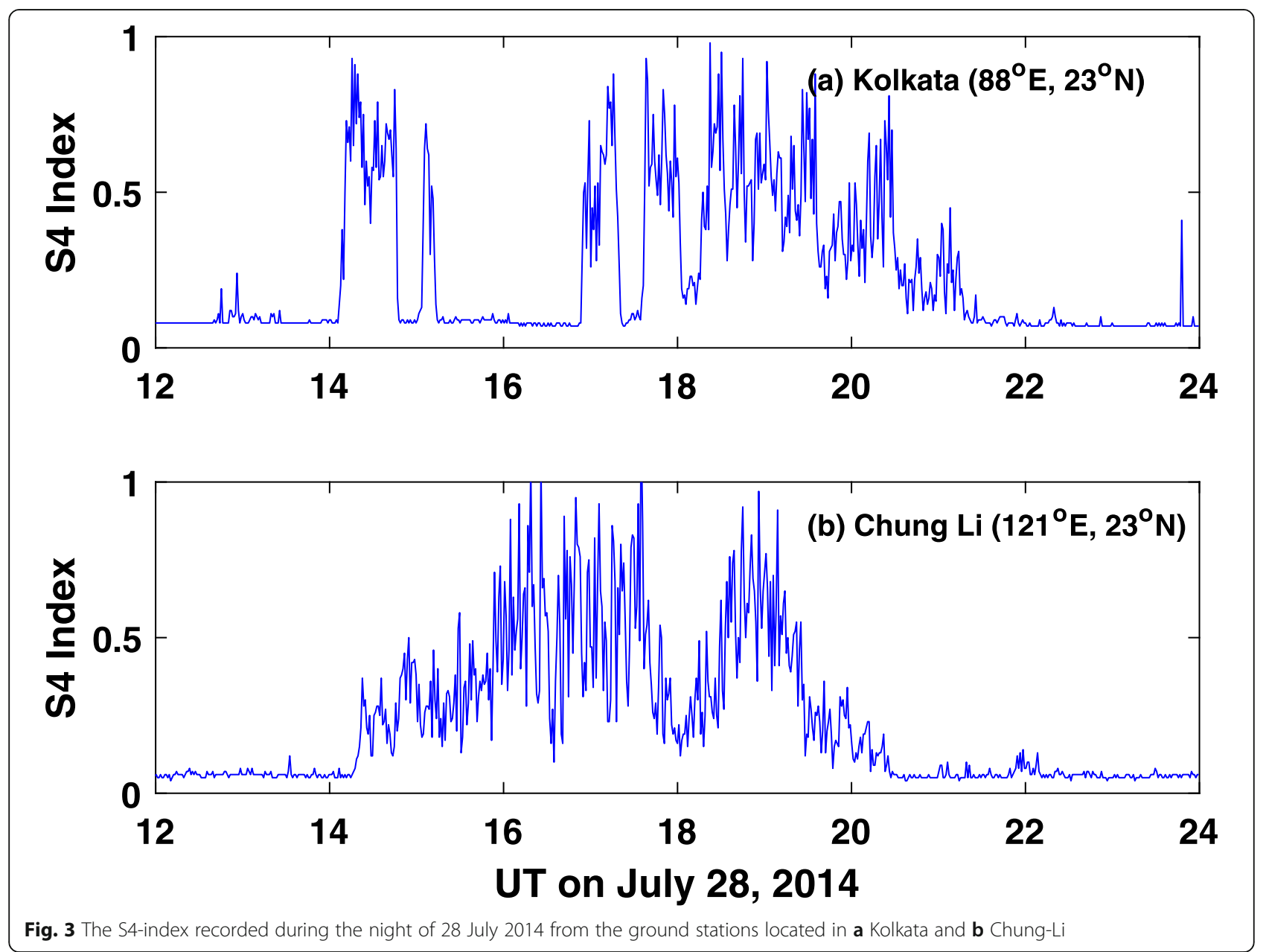

\section{Discussion}

From the results presented in Figs. 1, 2, and 3, it is evident that this unseasonal ESF/EPB event on 28 July 2014 is a large-scale plasma bubble activity spanning over a wide longitudinal sector from India, Indonesia, and Southeast Asian region. Carter et al. (2018, the companion paper) have also shown the widespread L-band scintillation activity over the longitudes of Indian and Southeast Asian region from COSMIC/Formosat-3 GPS-Radio Occultation observations. Further, Fig. 4 indicates that the EPB activity is completely absent over the Indonesian sector during the entire month of July 2014 except this singular event day (28th). Also, the VHF scintillation observations from Kolkata (India) and Chung-Li (Taiwan) exhibit no significant post-sunset scintillations other than on July 28 for the entire month (not shown in the figure). Carter et al. (2018) have already shown this unseasonal ESF event on 28 July 2014 is not associated with any disturbed geomagnetic activity. Further, this unseasonal ESF event is preceded by a substantial elevation of equatorial F-layer ( $h$ ' $F$ in Fig. 5a, b) compared to its monthly mean variation and day-to-day variability represented by the standard deviation (error bars) at both Indian and Indonesian sectors. This elevation of equatorial F-layer is mainly due to the large pre-reversal enhancement (PRE) in the zonal electric field, which is generally unexpected in the month of July due to the misalignment between the sunset terminator and magnetic meridian (Abdu et al. 1981; Tsunoda 1985). Hence, the causes behind the unusual enhancement of PRE on this event day remain to be the most intriguing question to be addressed here. Though the exact mechanisms responsible for the enhanced PRE are not clearly known, we put forth our views about the possible mechanisms hereunder.

There are three mechanisms generally proposed to explain the PRE in the literature: (i) the curl-free mechanism (CFM) by Rishbeth (1973) and Eccles (1998), (ii) Hall current divergence mechanism (HCDM) by Farley et al. (1986), and (iii) the EEJ feeding to PRE by 


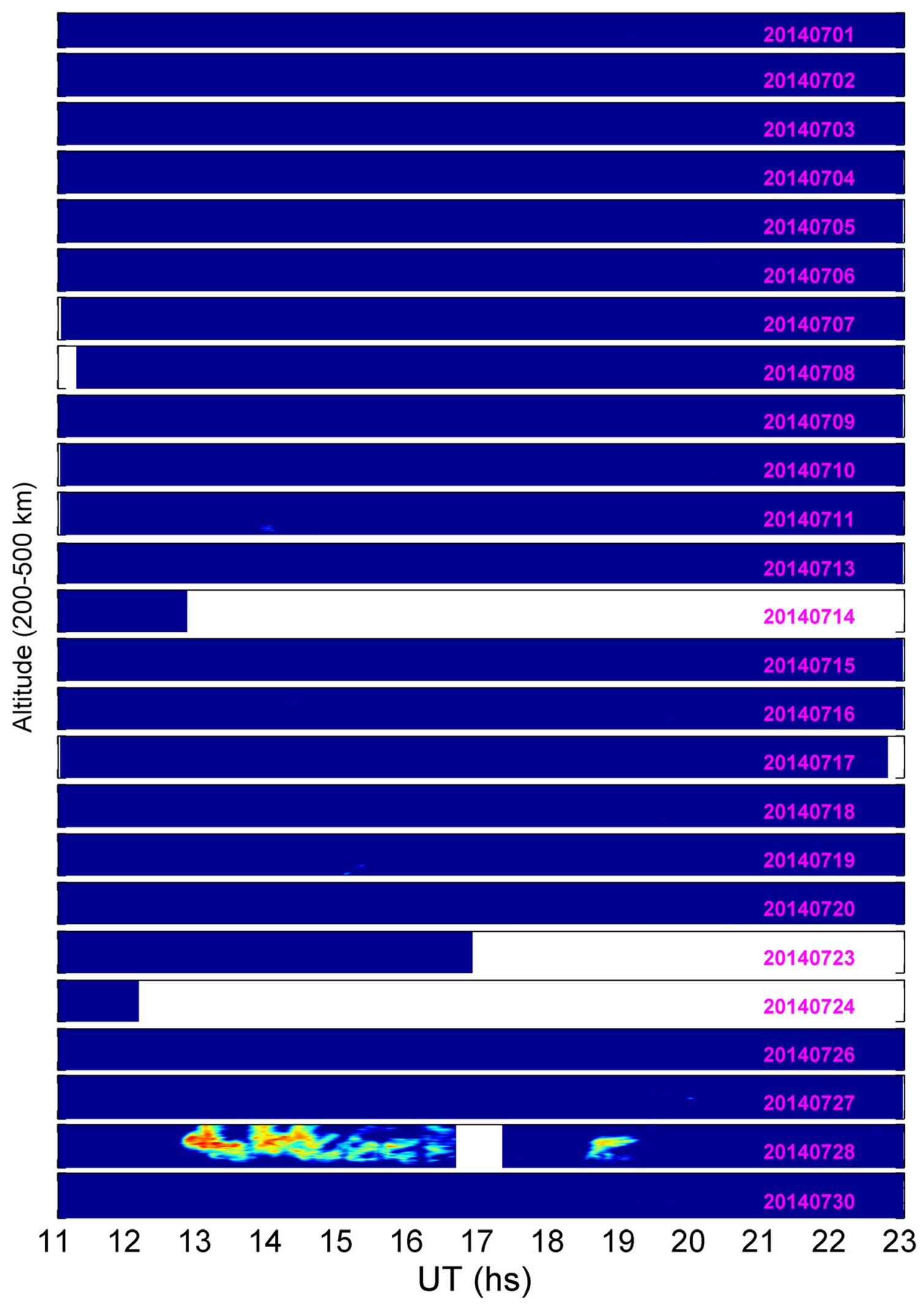

Fig. 4 The altitude-time-intensity (ATI) map of F-region backscatter echoes observed by the central beam of Equatorial Atmosphere Radar (EAR) for all days in July 2014 


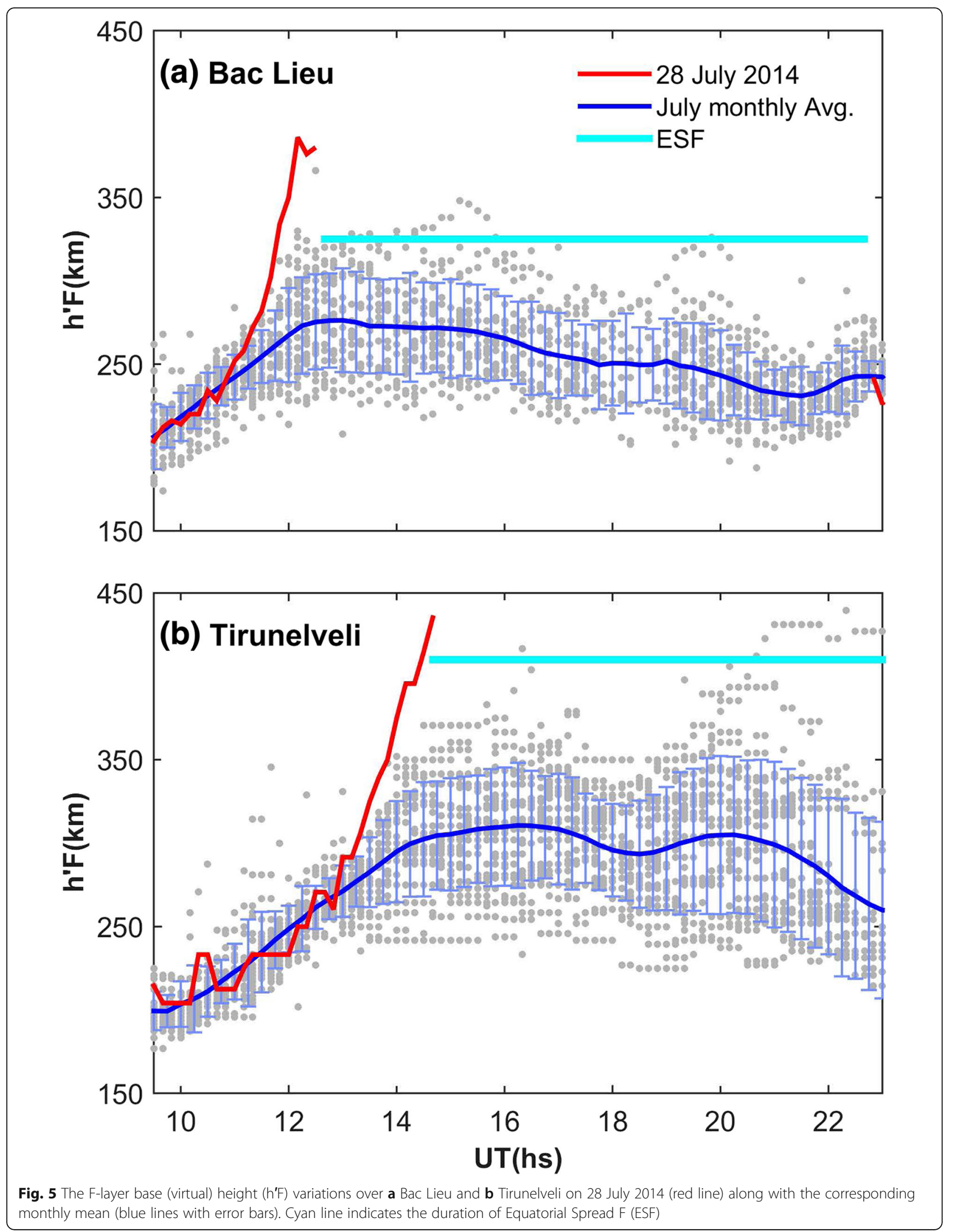


Haerendel and Eccles (1992). An excellent review on the three competing mechanisms and their relative importance can be found in Eccles et al. (2015). The CFM proposed by Rishbeth (1971, 1973) and Eccles (1998) indicates that the PRE magnitude is proportional to the longitudinal gradient in the downward polarization electric field generated by the F-region neutral wind dynamo. The HCDM by Farley et al. (1986) depends on the Hall conductivity gradient in the off-equatorial E-region and the associated divergence of Hall current which in turn is driven by the downward polarization electric fields generated by the F-region dynamo. Nevertheless, both the CFM and HCDM suggest that the downward polarization electric fields generated by the F-region dynamo region and the simultaneous decay of corresponding off-equatorial E-region conductivity hold the key for the PRE. Tsunoda (1985) has further shown that the rate of decay of total field-line-integrated E-region conductivity (combined E-region conductivities of both hemispheres) controls the magnitude of the PRE. The slower decay of off-equator E-region density in the summer hemisphere reduces the PRE magnitude during the solstices by short-circuiting the polarization electric fields generated by the F-region dynamo (Tsunoda 1985). Abdu et al. (2004) have shown that the PRE is very sensitive to local time/longitudinal gradient in the field-line-integrated E-region Pedersen conductivity. The declination angle of the geomagnetic field lines is nearly zero over the Indian and Indonesian sectors. July being the northern summer, the off-equatorial E-region sunset occurs later (earlier) in the northern (southern) magnetic hemisphere with respect to apex sunset over the equator. Therefore, the off-equatorial E-region conductivity in the northern hemisphere should generally be responsible for short-circuiting of dynamo electric fields during July. However, the large enhancement in PRE on this event day (July 28) over both Indian and Indonesian sectors indicates that the short-circuiting effect by the E-region conductivity is absent or kept minimum on this day for some reason, perhaps, due to the forces of lower atmospheric origin.

With a view to further investigate, the mesospheric neutral wind measurements over the Indian sector from medium frequency $(2 \mathrm{MHz})$ partial reflection $(\mathrm{PR})$ radar at an off-equatorial station, Kolhapur, were examined. The geographic location of the Kolhapur PR radar can be seen in Fig. 1. Figure 6 shows the meridional wind variation at $98 \mathrm{~km}$ altitude observed from the Kolhapur on July 28 (red curve). The blue curve with error bars represents the 30-day mean variation of meridional wind centered on July 28 (i.e., July $28 \pm 15$ days) and its standard deviation. The small vertical green arrow on the $X$-axis indicates the time of equatorial E-region $(100 \mathrm{~km})$ sunset over Indian $\left(78^{\circ} \mathrm{E}\right)$ sector. It can be noticed from

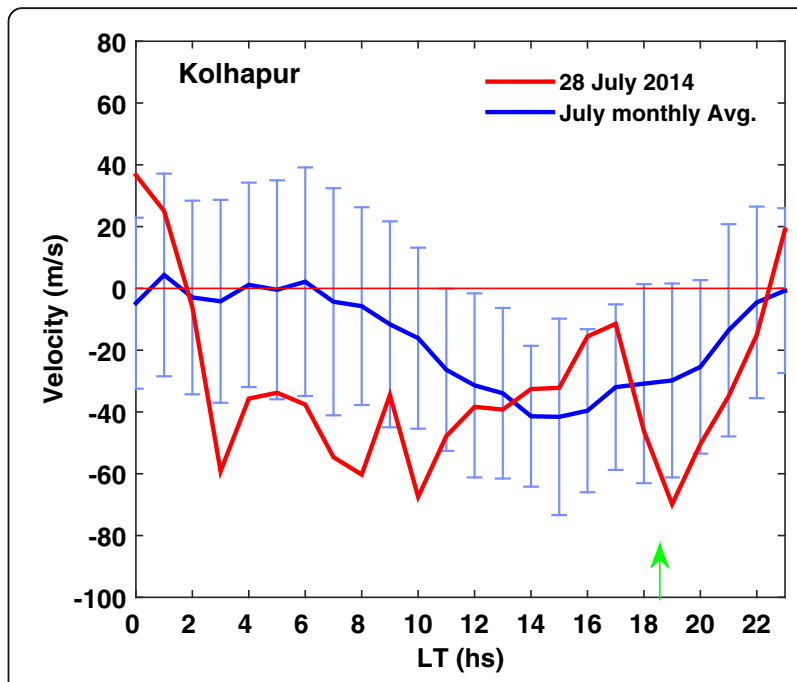

Fig. 6 The mesospheric meridional wind (positive northward) as a function of local time on 28 July 2014 (red line) and 30-day average (July $28 \pm 15$ days) centered on July 28 (blue line with error bar) observed by MF radar at Kolhapur. The small vertical green arrow indicates the time of equatorial E-region (100 km) sunset over Indian $\left(78^{\circ} \mathrm{E}\right)$ sector

this figure that the meridional wind on July 28 is significantly different from the reference 30 -day mean variation and largely southward throughout the day except for a brief interval around midnight. Around sunset ( $18.5 \mathrm{LT}$ ), the meridional wind turns largely southward (equatorward) and reaches approximately $-67 \mathrm{~m} / \mathrm{s}$, which is significantly large, compared to its mean value. Further, as will be shown later, this large equatorward wind is a part of quasi-2-day wave that maximizes at $90 \mathrm{~km}$ altitude with a vertical wavelength of $\sim 107 \mathrm{~km}$. Hence, the meridional wind can be assumed to be in the same phase (direction) over lower thermospheric altitudes of $\sim 90-140 \mathrm{~km}$ (i.e., $90+$ half of the vertical wavelength), however, with a varying magnitude.

The role of thermospheric meridional winds on the strength of PRE and ESF development has been reported in quite a few studies (e.g., Maruyama 1988; Devasia et al. 2002; Jyoti et al. 2004; Abdu et al. 2006a and references therein). Maruyama (1988) has shown that the summerto-winter transequatorial wind is an important factor controlling the generation of ESF. Assuming a latitudinally uniform transequatorial wind, Maruyama (1988) has shown that the growth rate of RT instability decreases due to the enhanced E-region field-line-integrated conductivity. Later, Devasia et al. (2002) and Jyoti et al. (2004) have suggested that the equatorward meridional wind could help to trigger the instability and ESF development even at lower F-layer heights. Further, Abdu et al. (2006a) have shown that the larger poleward meridional wind can reduce the PRE strength and suppress the ESF development. These studies directly or indirectly show that the 
equatorward (poleward) meridional wind would enhance (suppress) the PRE and ESF. More recently, Huba and Krall (2013) have shown that the equatorward neutral wind can cause an increase in an upward ExB drift (eastward electric field) at the equator by facilitating the polarization electric fields to grow due to a decrease in off-equatorial E-region conductivity. All the above studies mainly deal with thermospheric meridional winds around F-region altitudes. However, the meridional wind observations around F-region altitudes are not available for the present case. On the other hand, the Kolhapur PR radar observations indicate that the meridional wind is equatorward over lower thermospheric altitudes of $\sim 90$ to $140 \mathrm{~km}$. In order to examine the role of equatorward/poleward neutral wind over lower thermospheric altitudes on the off-equatorial E-region electron density and Pedersen conductivity, we have employed the SAMI2 (Sami2 is Another Model of the Ionosphere) (Huba et al. 2000) model simulations. Two controlled simulations were carried out with the meridional wind $(\mathrm{V})$ is set to $-60 \mathrm{~m} / \mathrm{s}$ (equatorward) and $+60 \mathrm{~m} / \mathrm{s}$ (poleward) over the altitudes 90 to $150 \mathrm{~km}$, and the zonal wind $(\mathrm{U})$ is set to zero for both cases. Figure 7a shows the local time variations of electron

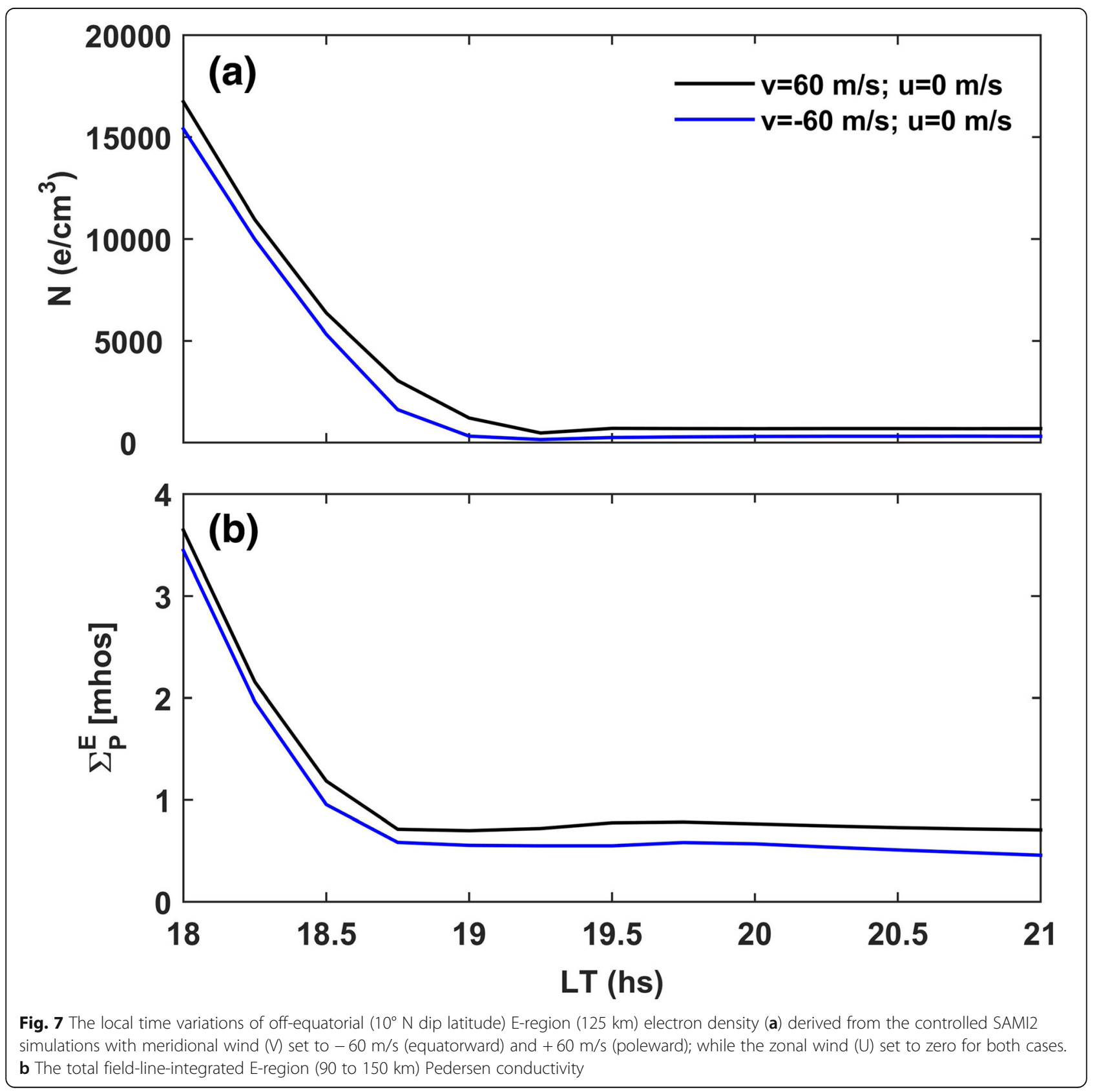


density over the off-equatorial location of $10^{\circ} \mathrm{N}$ dip latitude at $125 \mathrm{~km}$ altitude. Figure $7 \mathrm{~b}$ shows the local time variations of total field-line-integrated Pedersen conductivity over E-region altitudes $(90-150 \mathrm{~km})$. From the model simulations presented in Fig. 7a, b, it can be noticed that both E-region density and the field-line-integrated Pedersen conductivity exhibit a small decrease for the case of equatorward meridional wind (blue curves) compared to the case of poleward wind (black curves). Though the decrease in off-equatorial E-region density and fieldline-integrated Pedersen conductivity due to the equatorward meridional wind is small, it could have a significant influence on the PRE. For example, Fesen et al. (2000), through TIEGCM model simulations, have shown that a small decrease in E-region electron density from 3300 to $1500 \mathrm{~cm}^{-3}$ can cause a significant enhancement in PRE
(Fig. 1 of Fesen et al. 2000) as the PRE is highly sensitive to off-equator E-region density around sunset. Hence, one possible explanation could be that the enhanced equatorward neutral wind in lower thermospheric altitudes as observed from Kolhapur PR radar could cause a small decrease in E-region plasma density at off-equatorial latitudes via transport, particularly around sunset hours, where the production due to photoionization is minimum because of higher solar zenith angles. Another possible factor that could cause a significant reduction in E-region density is the divergent node of zonal wind shear via field perpendicular transport of plasma. However, presently, we do not have any observations to support the presence of zonal wind shear. Nevertheless, this decrease in off-equatorial E-region density (or field-line-integrated E-region Pedersen conductivity) could reduce (or remove)
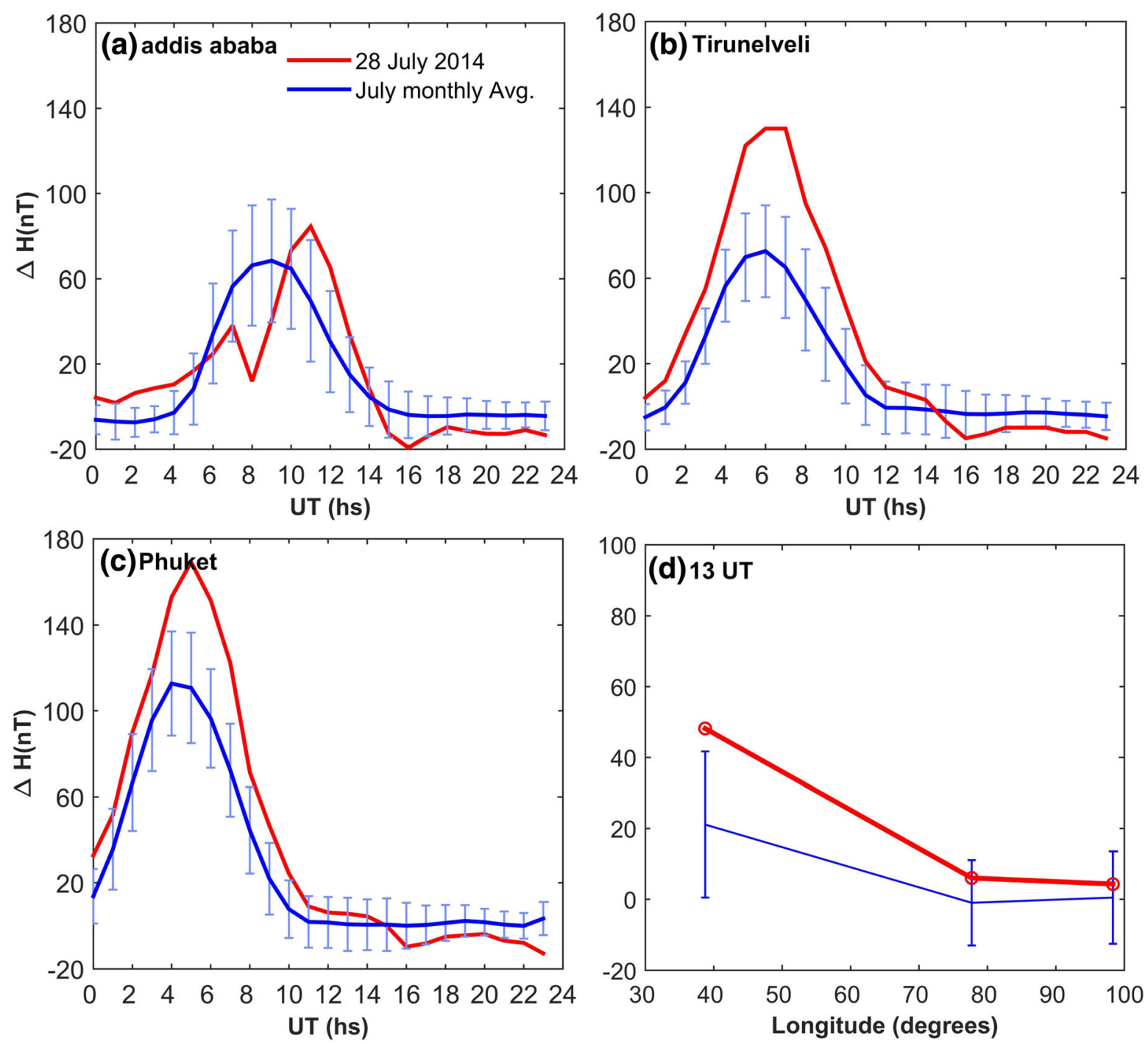

Fig. 8 The $\Delta H$ variation as a function of universal time on 28 July 2014 (red line) and July monthly average (blue line with error bar) observed by magnetometers over a Addis Ababa, b Tirunelveli, and $\mathbf{c}$ Phuket and $\mathbf{d}$ the longitudinal variation of $\Delta H$ values for 13 UT 
the effect of short-circuiting of the F-region dynamo electric fields in the summer hemisphere and that could lead to the enhancement in PRE.

Another mechanism proposed for PRE by Haerendel and Eccles (1992) is the role of equatorial electrojet (EEJ) feeding to the PRE at sunset terminator. Eccles et al. (2015) have shown that the magnitude of PRE is controlled by the longitudinal gradient in the EEJ from the dayside to nightside across the sunset terminator. Haerendel and Eccles (1992) and Eccles et al. (2015) have suggested that the PRE can lift the ionization out from the E-region to further reduce the Cowling conductance and provide a positive feedback for the increase of PRE magnitude. Thus, in order to examine the role of EEJ on the enhanced PRE on July 28, the magnetometer observations from three equatorial stations, Addis Ababa (Africa), Tirunelveli (India), and Phuket (Thailand), that are distributed from dayside to night were examined. The geographic locations of these magnetometer stations can be seen in Fig. 1. For example, Fig. $8 \mathrm{a}-\mathrm{c}$ show the variations of $\Delta H$ ( $H$ component of the geomagnetic field after subtracting the quiet day mean midnight value), which is a proxy to the EEJ, from Addis Ababa, Tirunelveli, and Phuket, respectively. The red curves indicate the $\Delta H$ variations on July 28 , and the blue curves with error bars represent the monthly mean variations with standard deviations. It can be seen from these figures that the $\Delta H$ at all the three stations are significantly enhanced on July 28 compared to their respective monthly mean variations. It should be noted that the $\Delta H$ variations measured from magnetometer actually represent the integrated current in the eastward direction which is proportional to both conductivity and zonal electric field $(\mathrm{J}=\sigma \cdot E)$. The Hall and Pedersen conductivities maximize at approximately $110 \mathrm{~km}$ and $125 \mathrm{~km}$ altitudes, respectively (Forbes and Lindzen 1976). Further, the zonal current enhances significantly at equatorial latitudes, called equatorial electrojet (EEJ) due to the Cowling effect. The Cowling conductivity maximizes around $\sim 105 \mathrm{~km}$ altitude (Forbes and Lindzen 1976). Hence, the major contribution for the $\Delta H$ variations measured from the equatorial magnetometers comes from the E-region altitudes due to the enhanced Cowling conductivity in the absence of other solar-driven geomagnetic disturbances (quiet periods). Figure $8 \mathrm{~d}$ shows the $\Delta H$ values from the three stations at 13 UT during which the Addis Ababa is in dayside, Tirunelveli is close to E-region sunset terminator, and Phuket is in the nightside. The longitudinal gradient of $\Delta H$ from dayside to nightside on July 28 (red curve) appears to be high compared to its monthly mean variation (blue curve with error bars). This large longitudinal gradient in EEJ on July 28 may also contribute to the enhanced PRE according to the mechanism proposed by Haerendel and Eccles (1992).
Therefore, from the results presented in Figs. 6, 7, and 8 , one can envisage that the background conditions such as large equatorward meridional wind at northern off-equatorial E-region (Fig. 6) and enhanced longitudinal gradient of equatorial electrojet from dayside to nightside (Fig. 8) might have caused the favorable conditions for the enhanced PRE and large-scale unseasonal ESF activity on 28 July 2014. The observed changes in the meridional wind and PRE on 28 July 2014 could have a connection with the wave forces of lower atmospheric origin. One of the clues that motivated our line of thinking about the possible role of planetary wave modulation on PRE comes from the daily variation of PSSR during 20-31 July 2014. For example, Fig. 9a, b shows the daily variation of PSSR (peak h'F during 1900-2100 LT) at the stations Bac Lieu and Tirunelveli, respectively. One can readily observe from Fig. 9a, b that the PSSR gradually increases from 20 July to 28 July with a quasi-2-day wave-like modulation at both stations. Further, the PSSR reached maximum on 28 July at both stations.

The results presented in Fig. 9 indicate that a quasi-2-day planetary wave from the lower atmospheric origin might have modulated the PSSR over Indian and

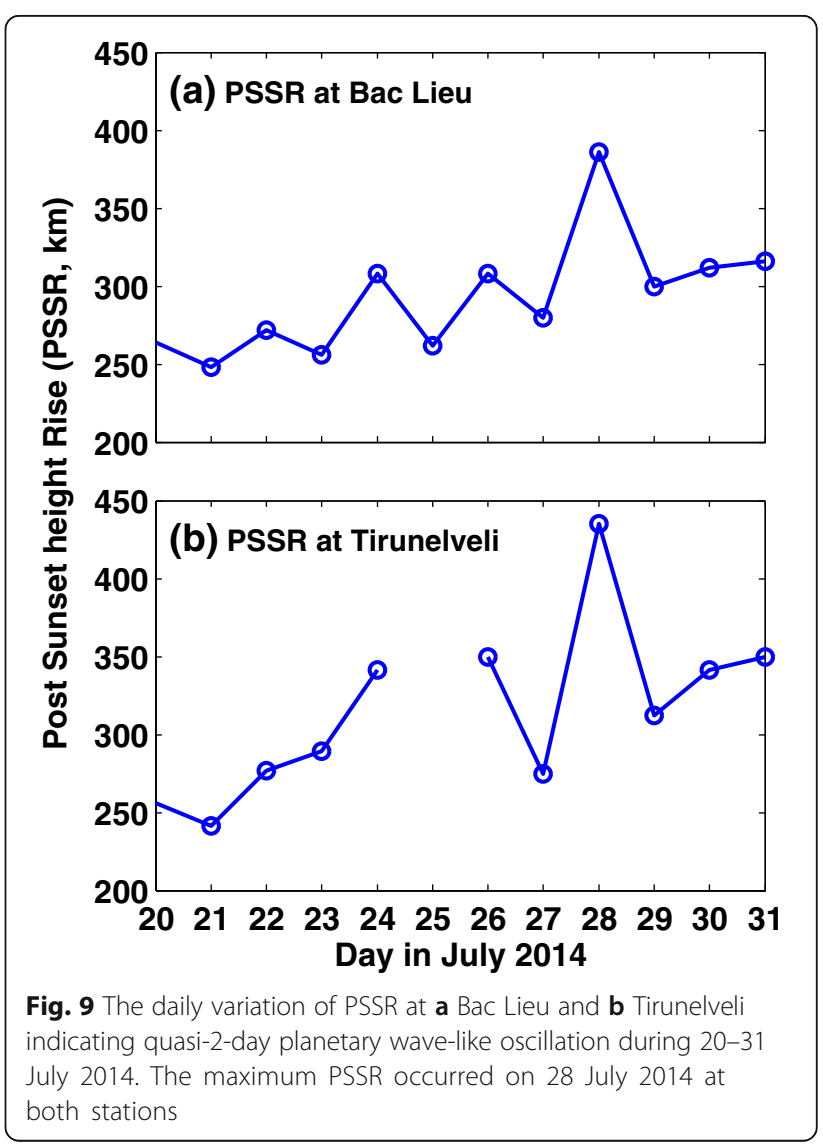


Southeast Asian region, possibly, through the modulation in the neutral wind. Abdu et al. (2006b) have shown the planetary wave $(\sim 2$ to 7 day $)$ oscillations in the mesospheric winds can cause similar oscillations in the equatorial evening pre-reversal electric field through $\mathrm{E}$ and F-region electro-dynamical coupling. With a view to
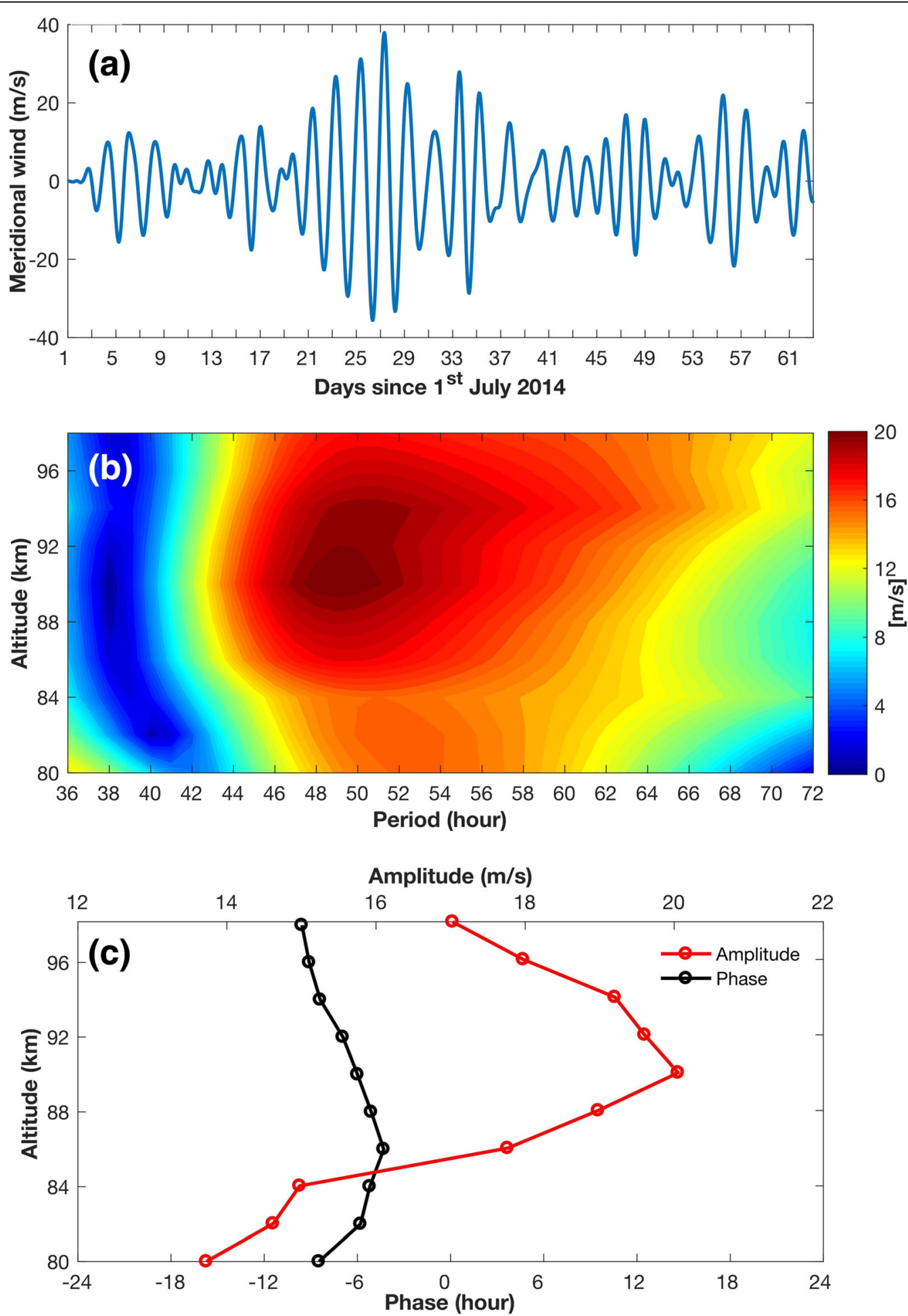

Fig. 10 a The 2-day planetary wave packet (1.5-2.5-day bandpass filtered) in the meridional wind from Indian low-latitude station, Kolhapur, during 01 July 2014-31 August 2014. b Amplitude spectra of meridional wind at 80-98 km altitudes showing the quasi-2-day wave periodicity of $\sim 48-52 \mathrm{~h}$. c Altitudinal variation of amplitude (red) and phase (black) of quasi-2-day wave taken at $48 \mathrm{~h}$ periodicity 
further examine this, the meridional neutral wind observations at $98 \mathrm{~km}$ altitude from the Kolhapur PR radar were analyzed using a digital bandpass filter. A Butterworth digital bandpass filter centered at $48 \mathrm{~h}$ (2 days) with a 3- $\mathrm{dB}$ bandwidth of $36-50 \mathrm{~h}$ (1.52.5 day) is applied on the time series data of hourly meridional wind observations during the months of July to August 2014. Figure 10a shows the filtered quasi-2-day wave oscillations in the meridional wind at $98 \mathrm{~km}$ altitude over Indian low-latitude station Kolhapur during July to August 2014. It can be seen from Fig. 10a that the quasi-2-day wave amplitude exhibits significant enhancement during 20-30 July 2014. Further, the amplitude of the quasi-2-day wave increases from 20 July and reaches a maximum around 27-28 July.

Figure 10b shows the amplitude spectra of meridional wind at altitudes from 80 to $98 \mathrm{~km}$ at $2 \mathrm{~km}$ interval during 20-30 July 2014 computed using least squares method (Malin and Schlapp 1980; Gu et al. 2013). The dominant quasi-2-day wave with a periodicity of $\sim 48$ $52 \mathrm{~h}$ can be observed at all altitudes. Figure 10c shows the altitude variations of amplitude and phase of quasi-2-day wave (at $48 \mathrm{~h}$ period). The quasi-2-day wave in the meridional wind maximizes at $\sim 90 \mathrm{~km}$, and the phase decreases gradually with the height. From the slope of the phase variation, the vertical wavelength of the quasi-2-day wave can be estimated as $107 \mathrm{~km}$. It is known that the vertical wavelengths of quasi-2-day wave are generally large of the order of $\sim 70-200 \mathrm{~km}$ (e.g., Gu et al. 2013). The large vertical wavelengths of quasi-2-day wave indicate that the meridional wind will be in the same phase (direction) over an altitude range of approximately half of the vertical wavelength. Therefore, it could be possible that the meridional wind would be in the same direction (equatorward) over lower thermospheric altitudes of $\sim 90-143 \mathrm{~km}$ in the present case. Abdu et al. (2006b) have shown that the neutral wind oscillations associated with the planetary waves can significantly alter the evening PRE via modulating the integrated E-region Pedersen conductivity. Therefore, a quasi2-day planetary wave in the meridional neutral wind might have caused a similar modulation in PSSR (Fig. 9) through the modulation of the E-region conductivity at off-equatorial latitudes (such as at Kolhapur) and PRE as discussed above (Fig. 6). This study indicates the possible role of planetary wave forces of lower atmospheric origin that can significantly modify the neutral wind at mesosphere and lower thermospheric (MLT) region and PRE system leading to the development of large PSSR and unseasonal large scale EPB/ESF activity. Nevertheless, modeling studies are further needed to substantiate this hypothesis.

\section{Conclusions}

An unseasonal enhancement of PRE and development of intense EPBs were observed over Indian and South East Asian longitudes during the post-sunset hours of 28 July 2014. Using multiple independent ground-based observations, the presence of intense EPBs over a wide longitudinal sector ranging from $77^{\circ} \mathrm{E}$ to $125^{\circ} \mathrm{E}$ is confirmed. The ATI maps of an EAR for the month of July 2014 indicate that the EPB development on July 28 is an unusual and unique event over this sector. The observations from two equatorial ionosondes at Tirunelveli and Bac Lieu show that F-layer is elevated to higher altitudes prior to the development of these post-sunset EPBs due to the pre-reversal enhancement of zonal electric field. The unusual enhancement of the PRE on this day might be due to the reduction of the E-region conductivity in the northern (summer) low latitudes probably due to enhanced equatorward meridional wind or divergent node of zonal wind shear. Further, it is also speculated that the large longitudinal gradient in equatorial electrojet may also conducive for the enhanced PRE according to the Haerendel and Eccles (1992) mechanism.

A quasi-2-day wave-like oscillation in the PSSR is consistently observed at both equatorial stations, Bac Lieu and Tirunelveli, during 20-31 July 2014. The maximum PSSR occurred on 28 July at both stations. A similar quasi-2-day wave-like oscillation in the meridional neutral wind with a large vertical wavelength of $\sim 107 \mathrm{~km}$ is observed at the off-equatorial station, Kolhapur, during 20-30 July 2014 with maximum amplitude on 28 July. This indicates the possible coupling between the 2-day planetary wave of lower atmospheric origin and PSSR over Indian and southeast Asian sector. This study emphasizes the coupling from lower atmosphere and the role of planetary wave forcing that can potentially alter the local wind system and E-region conductivities that can lead to the unusual enhancement of PRE and development of EPBs over the wide longitudinal sector, during the season which is climatologically unfavorable for EPBs.

\section{Abbreviations \\ ATI: Altitude-time-intensity; EEJ: Equatorial electrojet; EPB: Equatorial plasma bubble;" ESF: Equatorial Spread-F; FAl: Field-aligned irregularities; FoV: Field of view; HCDM: Hall current divergence mechanism; LSWS: Large-scale wave structure; MLT: Mesosphere and lower thermosphere; PR: Partial reflection; PRE: Pre-reversal enhancement; PSSR: Post-sunset height rise; RT: Rayleigh- Taylor; SCINDA: Scintillation Network Decision Aid; TIEGCM: Thermosphere- Ionosphere Electrodynamics General Circulation Model}

\section{Funding}

This work was supported by SERB-DST Sanction Number ECR/2017/002271 and JSPS KAKENHI Grant Number 15H02135

Availability of data and materials

Please contact M. Yamamoto (yamamoto@rish.kyoto-u.ac.jp) for EAR data, S. Gurubaran (gurubara@iigs.iigm.res.in) for Kolhapur PR data, T. Yokoyama (tyoko@nict.go.jp) for Bac Lieu ionosonde data, S. Sripathi 
(sripathi@iigs.iigm.res.in) for Tirunelveli ionosonde data, K. Hozumi (kukkai@nict.go.jp) for Phuket magnetometer data, and Keith Groves (keith.groves@bc.edu) for SCINDA VHF scintillation data. The magnetometer data of Tirunelveli is available from the World Data Center for Geomagnetism, Mumbai (http://wdciig.res.in/WebUl/Home.aspx) and the magnetometer data of Addis Ababa is available at Intermagnet (http://www.intermagnet.org/).

\section{Authors' contributions}

KK, ST, and BC proposed the topic and conceived and designed the study. ST and KK drafted the manuscript and carried out the data analysis. SSK and KK analyzed the meridional wind data measured from Kolhapur PR radar. MY contributed the EAR data. TY contributed the Bac Lieu ionosonde data. SG contributed the Kolhapur PR radar data. SS contributed Tirunelveli ionosonde data. KH contributed the Phuket magnetometer data. KG and RC provided the SCINDA VHF scintillation data of Kolkata and Chung-Li. All authors read and approved the final manuscript.

\section{Competing interests}

The authors declare that they have no competing interest.

\section{Publisher's Note}

Springer Nature remains neutral with regard to jurisdictional claims in published maps and institutional affiliations.

\section{Author details}

${ }^{1}$ Indian Institute of Geomagnetism, Navi Mumbai, India. ${ }^{2}$ RMIT University, Melbourne, Australia. ${ }^{3}$ Equatorial Geophysical Research Laboratory, Indian Institute of Geomagnetism, Tirunelveli, India. ${ }^{4}$ Research Institute for Sustainable Humanosphere (RISH), Kyoto University, Uji, Japan. ${ }^{5}$ National institute of Information and Communications Technology, Tokyo, Japan. ${ }^{6}$ Boston College, Boston, USA. ${ }^{7}$ Space Vehicles Directorate, Air Force Research Laboratory, Kirtland AFB, Albuquerque, NM, USA.

\section{Received: 31 August 2017 Accepted: 12 September 2018}

Published online: 03 October 2018

\section{References}

Abdu MA, Batista IS, Reinisch BW, Carrasco AJ (2004) Equatorial F-layer heights, evening prereversal electric field, and night E layer density in the American sector: IRI validation with observations. Adv Space Res 34:1953-1965.

Abdu MA, Batista PP, Batista IS, Brum CGM, Carrascp AJ, Reinisch BW (2006b) Planetary wave oscillations in mesospheric winds, equatorial evening prereversal electric field and spread F. Geophys Res Lett 33:L07107. https://doi.org/10.1029/2005GL024837.

Abdu MA, Bittencourt JA, Batista IS (1981) Magnetic declination control of the equatorial F region dynamo electric field development and spread F. J Geo phys Res 86:11443-11446.

Abdu MA, lyer KN, de Medeiros RT, Batista IS, Sobral JHA (2006a) Thermospheric meridional wind control of equatorial spread $\mathrm{F}$ and evening prereversal electric field. Geophys Res Lett 33:L07106. https://doi.org/10.1029/ 2005GL024835

Ajith KK, Ram ST, Yamamoto M, Yokoyama T, Gowtam VS, Otsuka Y, Tsugawa T, Niranjan K (2015) Explicit characteristics of evolutionary-type plasma bubbles observed from Equatorial Atmosphere Radar during the low to moderate solar activity years 2010-2012. J Geophys Res Space Phys 120:1371-1382. https://doi.org/10.1002/2014JA020878.

Ajith KK, Tulasi Ram S, Yamamoto M, Otsuka Y, Niranjan K (2016) On the fresh development of equatorial plasma bubbles around the midnight hours of June solstice. J Geophys Res Space Phys 121:9051-9062. https://doi.org/10. 1002/2016JA023024.

Anderson D, Anghel A, Chau J, Veliz O (2004) Daytime vertical E × B drift velocities inferred from ground-based magnetometer observations at low latitudes. Space Weather 2:S11001. https://doi.org/10.1029/2004SW000095.

Booker BB, Wells HW (1938) Scattering of radio waves by the F region of the ionosphere. J Geophys Res 43:249.

Carter BA, Retterer JM, Yizengaw E, Groves K, Caton R, McNamara L, Bridgwood C, Francis M, Terkildsen M, Norman R, Zhang K (2014b) Geomagnetic control of equatorial plasma bubble activity modeled by the TIEGCM with Kp. Geophys Res Lett 41:5331-5339.

Carter BA, Retterer JM, Yizengaw E, Wiens K, Wing S, Groves K, Caton R, Bridgwood C, Francis M, Terkildsen M, Norman R, Zhang K (2014C) Using solar wind data to predict daily GPS scintillation occurrence in the African and Asian low-latitude regions. Geophys Res Lett 41(23):8176-8184. https://doi.org/10.1002/2014GL062203.

Carter BA, Tulasi Ram S, Yizengaw E, Pradipta R, Retterer J, Norman R, Currie J, Groves K, Caton R, Terkildsen M, Yokoyama T, Zhang K (2018) Unseasonal development of F-region irregularities over Southeast Asia on 28 July 2014. Prog Earth Planet Sci 5:10. https://doi.org/10.1186/s40645-018-0164-y.

Carter BA, Yizengaw E, Retterer JM, Francis M, Terkildsen M, Marshall R, Norman R, Zhang K (2014a) An analysis of the quiet-time day-to-day variability in the formation of post-sunset equatorial plasma bubbles in the Southeast Asian region. J Geophys Res 119. https://doi.org/10.1002/2013JA019570.

Dao T, Otsuka Y, Shiokawa K, Tulasi Ram S, Yamamoto M (2016) Altitude development of postmidnight $\mathrm{F}$ region field-aligned irregularities observed using Equatorial Atmosphere Radar in Indonesia. Geophys Res Lett 43:1015-1022. https:/doi.org/10.1002/2015GL067432

Devasia CV, Jyoti N, Subbaro KSV, Viswanathan KS, Tiwari D, Sridharan R (2002) On the plausible leakage of thermospheric meridional winds with equatorial spread F. J Atmos Sol Terr Phys 64:1.

Eccles JV (1998) Modeling investigation of the evening pre-reversal enhancement of the zonal electric field in the equatorial ionosphere. J Geophys Res 103: 26,709-26,719. https://doi.org/10.1029/98JA02656.

Eccles JV, St. Maurice JP, Schunk RW (2015) Mechanisms underlying the prereversal enhancement of the vertical plasma drift in the low-latitude ionosphere. J Geophys Res Space Phys 120:4950-4970. https://doi.org/10. 1002/2014JA020664.

Farley DT, Balsley BB, Woodman RF, McClure JP (1970) Equatorial Spread F: implications of VHF radar observations. Geophys Res Lett 75:7199.

Farley DT, Bonelli E, Fejer BG, Larsen MF (1986) The prereversal enhancement of the zonal electric field in the equatorial ionosphere. J Geophys Res 91: $13,723-13,728$

Fejer BG, Scherliess L, de Paula ER (1999) Effects of the vertical plasma drift velocity on the generation and evolution of equatorial Spread F. J Geophys Res 104(A9):19,859-19,869. https://doi.org/10.1029/1999JA900271.

Fesen CG, Crowley G, Roble RG, Richmond AD, Fejer BG (2000) Simulation of the pre-reversal enhancement in the low latitude vertical ion drifts. Geophys Res Lett 27(13):1851-1854.

Forbes JM, Lindzen RS (1976) Atmospheric solar tides and their electrodynamic effects. II. The equatorial electrojet. J Atmos Terr Phys 38:911.

Fukao S, Hashiguchi H, Yamamoto M, Tsuda T, Nakamura T, Yamamoto MK, Sato T, Hagio M, Yabugaki Y (2003) Equatorial Atmosphere Radar (EAR): system description and first results. Radio Sci 38(3):1053. https://doi.org/10.1029/ 2002RS002767.

Groves KM et al (1997) Equatorial scintillation and systems support. Radio Sci 32(5):2047-2064

Gu S-Y, Li T, Dou X, Wang N-N, Riggin D, Fritts D (2013) Long-term observations of the quasi two-day wave by Hawaii MF radar. J Geophys Res 118:7886-7894 https://doi.org/10.1002/2013JA018858

Gurubaran S, Rajaram R (1999) Long-term variability in the mesospheric tidal winds observed by MF radar over Tirunelveli $\left(8.7^{\circ} \mathrm{N}, 77.8^{\circ} \mathrm{E}\right)$. Geophys Res Lett 26:1113-1116. https://doi.org/10.1029/1999GL900171.

Haerendel, G. (1973), Theory of Equatorial Spread F, Report, Max-Planck Inst. for Phys., and Astrophys, Garching, Germany.

Haerendel G, Eccles JV (1992) The role of the equatorial electrojet in the evening ionosphere. J Geophys Res 97:1181-1192. https://doi.org/10.1029/91JA02227.

Huang C, Hairston MR (2015) The postsunset vertical plasma drift and its effects on the generation of equatorial plasma bubbles observed by the C/NOFS satellite. J Geophys Res Space Phys 120:2263-2275. https://doi.org/10.1002/2014JA020735.

Huba JD, Joyce G, Fedder JA (2000) Sami2 is Another Model of the lonosphere (SAMI2), a new low-latitude ionosphere model. J Geophys Res 105:23,035-23,053. https://doi.org/10.1029/2000JA000035.

Huba JD, Krall J (2013) Impact of meridional winds on equatorial spread F: revisited. Geophys Res Lett 40:1268-1272. https://doi.org/10.1002/grl.50292.

Jyoti N, Devasia CV, Sridharan R, Tiwari D (2004) Threshold height (h'F)C for the meridional wind to play a deterministic role in the bottom side equatorial spread F and its dependence on solar activity. Geophys Res Lett 31:L12809. https://doi.org/10.1029/2004GL019455.

Kelley MC, Makela JJ, de La Beaujardière O, Retterer J (2011) Convective ionospheric storms: a review. Rev Geophys 49:RG2003. https://doi.org/10. 1029/2010RG000340.

Kelley MC, Maruyama T (1992) A diagnostic model for equatorial Spread F, 2, the effect of magnetic activity. J Geophys Res 97:1271-1277. 
Kelley MC, McClure JP (1981) Equatorial spread-F: a review of recent experimental results. J Atmos Terr Phys 43:427.

Kumar S, Chen W, Liu Z, Ji S (2016) Effects of solar and geomagnetic activity on the occurrence of equatorial plasma bubbles over Hong Kong. J Geophys Res Space Physics 121:9164-9178. https://doi.org/10.1002/2016JA022873.

Li G, Ning B, Liu L, Ren Z, Lei J, Su S (2007) The correlation of longitudinal seasonal variations of evening equatorial pre-reversal drift and of plasma bubbles. Ann Geophys 25:2571-2578.

Malin SRC, Schlapp DM (1980) Geomagnetic lunar analysis by least-squares. Geophys J R Astron Soc 60:409-418.

Maruyama T (1988) A diagnostic model for equatorial spread F 1, model description and application to electric field and neutral wind effects. J Geophys Res 93:14611-14622.

Maruyama T, Matuura N (1984) Longitudinal variability of annual changes in activity of equatorial spread F and plasma bubbles. J Geophys Res 89:10,903-10,912.

Otsuka Y, Ogawa T, and Effendy (2009) VHF radar observations of night time F-region field-aligned irregularities over Kototabang, Indonesia. Earth Planets Space 61:431-437. https://doi.org/10.1186/BF03353159.

Rama Rao PVS, Tulasi Ram S, Niranjan K, Prasad DSWD, Gopikrishna S, Lakshmi NKM (2005) VHF and L-band scintillation characteristics over Indian lowlatitude station, Waltair. Ann Geophys 23:2457-2464.

Rastogi RG (1980) Seasonal and solar cycle variations of equatorial spread $F$ in the American zone. J Atmos TerrPhys 42:593.

Retterer JM, Gentile LC (2009) Modeling the climatology of equatorial plasma bubbles observed by DMSP. Radio Sci 44:RSOA31. https://doi.org/10.1029/ 2008RS004057.

Rishbeth H (1971) Polarization field produced by winds in the ionospheric F region. Planet Space Sci 19:357.

Rishbeth H (1973) Further studies of directional F-layer currents. Planet Space Sci. 19:357-369.

Scherliess L, Fejer BG (1999) Radar and satellite global equatorial F region vertical drift model. J Geophys Res 104(A4):6829-6842. https://doi.org/10.1029/ 1999JA900025.

Tsunoda RT (1985) Control of the seasonal and longitudinal occurrence of equatorial scintillations by the longitudinal gradient in integrated $\mathrm{E}$ region Pedersen conductivity. JGeophys Res 90:447.

Tsunoda RT (2005) On the enigma of day-to-day variability in equatorial spread F. Geophys Res Lett 32:L08103. https://doi.org/10.1029/ 2005GL022512.

Tsunoda RT, White BR (1981) On the generation and growth of equatorial backscatter plumes: 1. Wave structure in the bottomside F layer. J Geophys Res 86:3610-3616.

Tsunoda RT, Yamamoto M, Tsugawa T, Hoang TL, Tulasi Ram S, Thampi SV, Chau HD, Nagatsuma T (2011) On seeding, largescale wave structure, equatorial spread F, and scintillations over Vietnam. Geophys Res Lett 38:L20102. https://doi.org/10.1029/2011GL049173.

Tulasi Ram S, Rama Rao PVS, Niranjan K, Prasad DSWD, Sridharan R, Devasia CV, Ravindhran S (2006) The role of post sunset vertical drifts at the equator in predicting the onset of VHF scintillations during high and low sunspot activity years. Ann Geophys 24:1609-1616. https://doi.org/10.5194/angeo-241609-2006.

Tulasi Ram S, Rama Rao PVS, Prasad DSWD, Niranjan K, Gopi Krishna S, Sridharan R, Ravindran S (2008) Local time dependent response of postsunset ESF during geomagnetic storms. J Geophys Res 113:A07310. https://doi.org/10. 1029/2007JA012922.

Tulasi Ram S, Rama Rao PVS, Prasad DSWD, Niranjan K, Raja Babu A, Sridharan R, Devasia CV, Ravindran S (2007) The combined effects of electrojet strength and the geomagnetic activity (Kp index) on the post sunset height rise of the $\mathrm{F}$ layer and its role in the generation of ESF during high and low solar activity periods. Ann Geophys 25:2007-2017.

Tulasi Ram S, Yamamoto M, Tsunoda RT, Chau HD, Hoang TL, Damtie B, Wassaie M, Yatini CY, Manik T, Tsugawa T (2014) Characteristics of large-scale wave structure observed from African and Southeast Asia longitudinal sectors. Geophys Res Space Physics 119:1-10. https://doi.org/10.1002/2013JA019712.

Tulasi Ram S, Yamamoto M, Tsunoda RT, Thampi SV (2012) On the application of differential phase measurements to study the zonal large scale wave structure (LSWS) in the ionospheric electron content. Radio Sci 47:RS2001. https://doi.org/10.1029/2011RS004870.

Woodman RF (2009) Spread F-an old equatorial aeronomy problem finally resolved? Ann Geophys 27:1915-1934. https://doi.org/10.5194/angeo-271915-2009.

\section{Submit your manuscript to a SpringerOpen ${ }^{\circ}$ journal and benefit from:}

- Convenient online submission

- Rigorous peer review

- Open access: articles freely available online

- High visibility within the field

- Retaining the copyright to your article

Submit your next manuscript at $\boldsymbol{\nabla}$ springeropen.com 